\title{
Primary age-related tauopathy and the amyloid cascade hypothesis: the exception that proves the rule? \\ John F. Crary
}

Department of Pathology, Fishberg Department of Neuroscience, Friedman Brain Institute, Ronald M. Loeb Center for Alzheimer's Disease, Icahn School of Medicine at Mount Sinai, USA

\section{Article Info}

\section{Article Notes}

Received: August 05, 2016

Accepted: September 21, 2016

\section{*Correspondence:}

Dr. John F. Crary, MD-PhD

Associate Professor, Department of Pathology

Fishberg Department of Neuroscience, Friedman Brain Institute, Ronald M. Loeb Center for Alzheimer's Disease, Icahn School of Medicine at Mount Sinai, 1 Gustave L. Levy Place Box 1194 New York, NY 10029, USA

Telephone: (212) 659-8695

Email: john.crary@mountsinai.org

(c) 2016 Crary JF. This article is distributed under the terms of the Creative Commons Attribution 4.0 International License

\section{ABSTRACT}

Extensive data supports the amyloid cascade hypothesis, which states that Alzheimer's disease (AD) stems from neurotoxic forms of the amyloid-beta $(A \beta)$ peptide. But the poor correlation between $A \beta$ plaques and neurodegeneration/cognitive impairment, the spaciotemporal disparity between $A \beta$ and tau pathology, and the disappointing results following several large clinical trials using $A \beta$-targeting agents are inconsistent with this explanation. The most perplexing inconsistency is the existence of AD-type dementia patients that develop abundant neurofibrillary tangles that are indistinguishable from those in early to moderate-stage $A D$ in the absence of compelling evidence of amyloid toxicity. This neuropathological phenotype, which is distinct from other diseases with tangles, represents a conceptual disconnect, because it does not fall within any previously established category of tauopathy and ostensibly invalidates the amyloid cascade hypothesis. Instead, recent efforts have led to consensus criteria for a new alternative diagnostic category, which presupposes that these tangle-only dementia patients represent extreme examples of a distinct primary age-related tauopathy (PART) that is universally observed, albeit to varying degrees, in the aging brain. The cause of PART is unknown, but sufficient evidence exists to hypothesize that it stems from an $A \beta$-independent mechanism, such as mechanical injury. Should the PART hypothesis withstand further experimental testing, it would represent a shift in the way a subset of subjects with $A D$ neuropathological change are classified and has the potential to focus and reaffirm the amyloid cascade hypothesis.

\section{Emergence of the amyloid cascade hypothesis}

In 1906, Alois Alzheimer observed a progressive dementing illness in a 55-year-old woman ${ }^{1}$. Using a new Bielschowsky silver stain, he observed the co-occurrence of amyloid plaques, previously described by Blocq and Marinescu, alongside a distinctive new lesion, termed the neurofibrillary tangle (NFT). The moniker Alzheimer's disease (AD), promulgated by Emil Kraepelin, was originally applied strictly to early-onset (i.e., pre-senile) dementia patients. But later, the term was broadened to encompass all dementia patients where plaques and tangles could be observed.

A series of findings provided the foundation for the amyloid cascade hypothesis, which maintains that increased $A \beta$ is the root cause of both rare familial and the more common sporadic forms of $\mathrm{AD}^{2}$. All other features (e.g., synaptic dysfunction, neurodegeneration, and cognitive impairment) were considered secondary, including NFT. Mutations in genes that influence $A \beta$ production (i.e., presenilin 1 , presenilin 2 and the amyloid precursor protein) cause familial early-onset $\mathrm{AD}^{3-6}$. Patients with trisomy 21 (Down syndrome) have triplication of the $A P P$ gene and essentially all develop $\mathrm{AD}^{7}$. Further, $A P O E \varepsilon 4$, the strongest risk allele for late-onset $\mathrm{AD}$, is strongly associated with $A \beta$ deposition ${ }^{8}$. Together with the argument that all patients with $A D$ have $A \beta$ deposition, though tautological because 
the diagnostic criteria require plaques, reinforced the assertion that $A \beta$ is the primary cause. The hypothesis has undergone revisions, but in essence remains intact $t^{9,10}$.

\section{Challenges in applying the amyloid cascade hypothesis}

Applying the framework provided by the amyloid cascade hypothesis to diagnosing and treating $\mathrm{AD}$ has proven problematic ${ }^{11-16}$. Early neuropathological criteria for diagnosing $\mathrm{AD}$ focused on $\mathrm{A} \beta$ burden ${ }^{11}$, but this strategy was not optimal given that total $A \beta$ plaques correlate poorly with cognitive impairment and neuronal loss ${ }^{17}$. Many investigators feel that the relevant lesion is the neuritic amyloid plaque, a distinct subtype that is differentiated by the presence of tau-positive neurites. The CERAD criteria, based on semiquantitative assessments of neuritic amyloid plaques, reflects this position ${ }^{18}$. To address the poor correlation between plaques and cognitive impairment, the CERAD criteria also consider $\mathrm{AD}$ as a clinicopathological diagnosis, requiring premortem evidence of cognitive dysfunction for a diagnosis of definite AD. Some investigators maintain that $\mathrm{AD}$ is a disease of both plaques and tangles. Thus, the NIA-Reagan neuropathological criteria were developed ${ }^{19}$. These 1997 criteria deploy both CERAD and the Braak NFT staging system, an approach based on the supposition that tau pathology progresses in a stereotyped hierarchical manner from the entorhinal cortex, through medial temporal lobe structures and eventually diffusely throughout the neocortex ${ }^{20,21}$. This system was later revised to incorporate early brainstem pathology. Another staging scheme for amyloid plaque progression, the Thal phase, assesses the progression of amyloid from neocortex, to limbic structures and ultimately cerebellum and brainstem. The recent NIAAA "ABC" system deploys Thal, Braak NFT and CERAD assessments. These 2012 criteria notably abandon the requirement of a premortem clinical dementia diagnosis, a requirement that was suggested to impede efforts to study patients with early presymptomatic and prodromal disease.

Several large phase III clinical trials of therapeutics targeting $A \beta$ have failed due to lack of efficacy, prompting reflection as to whether the amyloid cascade hypothesis is invalid $^{22,23}$. The reason for these failures remain unclear, but some investigators have cited these failed trials as evidence refuting the amyloid cascade hypothesis. Other investigators and pharmaceutical companies have concluded that the design of the trials, which failed to confirm target engagement, were the reason. Another possibility is that $A \beta$ triggers a complex neurodegenerative cascade with a late amyloid-independent phase ${ }^{24}$. The future success of an $A \beta$-targeting agent is required for final validation of the amyloid cascade hypothesis.
Advances in neuropathological sub-classification of dementia singles out tangle-only pathology

While the heterogeneity of dementing illnesses has complicated efforts to understand the relationship between $A \beta$ and cognitive failure, recent progress in understanding non-AD dementias has put $\mathrm{AD}$ into sharper focus. Some of pathologies are more readily differentiated from $\mathrm{AD}$ neuropathologically, such as vascular dementia, but this can be difficult to quantify. The TDP-43 proteinopathies (e.g., frontotemporal lobar degeneration, amyotrophic lateral sclerosis and hippocampal sclerosis-aging/ cerebral age-related TDP-43 with sclerosis (CARTS) are largely devoid of $A \beta$ and tau pathology ${ }^{25}$. The more closely overlapping "plaque-only dementia" cases were found to largely represent an $\alpha$-synucleinopathy (i.e., diffuse Lewy body disease) ${ }^{26}$.

The discovery of MAPT mutation in rare families demonstrating that tau dysfunction alone is sufficient to cause neurodegeneration represented a major breakthrough. But such cases are rare with a distinct frontotemporal dementia syndrome ${ }^{27}$. The degenerative movement disorders (e.g., Parkinson's disease, progressive supranuclear palsy and corticobasal degeneration) are readily differentiated from $A D$ clinically and neuropathologically by differences in regional vulnerability and distinctive glial pathology ${ }^{28}$. Chronic traumatic encephalopathy (CTE), first described in professional boxers, has received greater scrutiny because of the recent link to contact sports, particularly American football, and recent consensus criteria have greatly improved our ability to recognize this pathology ${ }^{29}$.

Another pattern of degeneration, however, which has been variably called tangle-only dementia (TOD), neurofibrillary tangle predominant senile dementia, tangle-dominant dementia, among many other monikers, has received far less attention ${ }^{30}$. But large dementia autopsy series designed to advance our understanding of AD have allowed TOD to come into sharper focus and culminated in the development of a new diagnostic category termed primary age-related tauopathy (PART). New consensus criteria place TOD on a continuum with age-related tangles, that are universally observed in aged brains ${ }^{31}$. Considerable evidence (see below) indicates that subjects with PART have a distinct constellation of features that sets them apart from classical "plaque and tangle" AD and other tauopathies. Studying these differences may provide clues to the pathogenesis of tauopathies and refine the amyloid cascade hypothesis.

\section{Neuropathological and clinical features of PART}

The NFT in PART are essentially identical to those observed in $\mathrm{AD}^{31}$. They are composed of similar tau isoforms ( 3 and 4 repeat), form paired-helical filaments, and are concentrated within neurons. The NFT in PART 
are localized to the medial temporal lobe in a distribution corresponding to up to Braak IV. NFT in this distribution can be observed in subjects with normal cognition, mild cognitive impairment and dementia. In cognitively normal elderly subjects, autopsy studies have demonstrated that medial temporal lobe NFT are essentially universal and in a more limited distribution in many younger individuals. In demented subjects, approximately $2-10 \%$ of subjects display such tangles without significant amyloid deposition ${ }^{31}$. The proportion of subjects with age-associated memory impairment or mild-cognitive impairment in association with PART might be high. There are a very large number of subjects within the biomarker/imaging-defined category of suspected non-amyloid pathophysiology (SNAP) which has overlap with $\mathrm{PART}^{32}$. Finally, given that $\mathrm{A} \beta$-deposition is commonly encountered in cognitively normal subjects, "benign $A \beta$ " deposits might be masking an underlying tauopathy in some patients leading to reduced prevalence estimates. Methods for differentiating PART tangles and AD tangles (e.g., biochemical or immunohistochemical markers) would be extremely helpful for answering this question.

Tangle-only dementia (TOD) was first described in a series of patients with clinical features that were very similar to those of classical $\mathrm{AD}^{30}$. While this category likely included some subjects with other dementing tauopathies, a large proportion have PART as a primary pathological dementing process. Key features of TOD that differentiate such subjects are older age of death, a female predominance and a somewhat milder amnestic dementia. While the degree of cognitive impairment can be severe in some subjects, it is our impression that many of such subjects have mixed pathology, often vascular disease (unpublished observations). Other psychotic symptoms have been observed, but this needs further clarification. More work needs to be done to further delineate the clinical and neuropathological spectrum of PART.

\section{Beyond A $\beta$ : drivers of PART}

What exactly PART represents has been the matter of debate, with various investigators considering it an $\mathrm{AD}$ variant, a frontotemporal dementia variant, or normal (or "pathological") aging. Toxins and infectious causes are also possible, but less likely ${ }^{33,34}$. Currently, the evidence fails to support a role for $A \beta$ toxicity in PART. Subjects with PART have no $\mathrm{A} \beta$ deposition, no association with $A P O E \varepsilon 4$, and biochemistry fails to show evidence of increased soluble $\mathrm{A} \beta$ in PART brain parenchyma ${ }^{35}$. Another hypothesis, that postulates early $A \beta$-dependent and subsequent $A \beta$ independent phases, is theoretically possible ${ }^{24}$. However, evidence supporting this notion is lacking and how it would be tested experimentally is unclear. Thus, $A \beta$-dependent mechanisms are unlikely to play a pathogenic role in PART.

Neither imbalances in tau splicing nor mutations in the tau gene have been found in PART $^{35}$. However, the microtubule-associated protein tau gene (MAPT) H1 haplotype, a risk allele that is associated with other tauopathies without a coding region mutation, has been investigated, suggesting an association with the $\mathrm{H} 1$ haplotype ${ }^{35,36}$. Together, an emerging theme suggests that PART dementia patients have genetic features that protect from amyloid accumulation but also alleles that serve as risk factors for tauopathy. Future studies are required to fully address this possibility.

The possibility that PART is a form of pathological brain aging deserves attention. Mechanical injury in the form of mild yet repetitive traumatic brain injury (TBI) is an established trigger for tauopathy in chronic traumatic encephalopathy (CTE) in elite athletes and boxers ${ }^{37}$. While subjects develop PART in the absence of documented TBI, the hypothesis that these tangles are caused by very mild repetitive "wear and tear" type injury can be supported by three arguments. First, the geometry of the human central nervous system is such that foci of mechanical stress concentration are predicted to include the medial temporal lobe and basal forebrain. Second, the presence of an uncal notch in the medial temporal lobe that overlies the transentorhinal cortex is very common even in the absence of cerebral edema ${ }^{38}$, providing direct physical evidence that this site is a focus of stress concentration. Third, patients with known repetitive mechanical brain injury (i.e., CTE) develop tangles in an overlapping distribution, however more widespread and of greater magnitude ${ }^{39}$. Thus, it is reasonable to hypothesize that the cause of PART is a very mild repetitive mechanical "wear and tear" type of agerelated injury.

\section{Criticism of the PART hypothesis}

Some investigators have suggested that PART and AD should not be differentiated ${ }^{40,41}$. Instead, they maintain that an analytical approach should be used. This argument, based on the frequency of amyloid and tau lesions in the brain over the aging spectrum, presupposes that all PART subjects will eventually develop amyloid plaques had they lived long enough. The fact that the burden of amyloid pathology decreases in centenarians does not support this conclusion ${ }^{42}$. Also, PART dementia subjects are generally very old, have end stage tauopathy with frequent ghost tangles, and marked atrophy and gliosis, but in a restricted in distribution, suggesting that they are at the end of their disease course, rather than the beginning and argues against the hierarchical progression model in these patients. Another criticism of the PART hypothesis is that the cause of both PART and classical late-onset AD continue to be unknown. Without causality established, it is impossible to know with absolute certainty that these represent two distinct processes rather than different manifestations of a common "dual" pathway as has been hypothesized ${ }^{43}$. 


\section{Conclusion}

Sufficient evidence exists to argue that PART represents a distinct pathological category, and the rapid adoption of the terminology indicates that practicing neuropathologists find utility in the terminology. This new conceptual framework will provide physician scientists and basic researchers with a new approach to stratifying subjects with AD neuropathological change, especially at the earliest stages when there is the highest likelihood of interventions achieving therapeutic success. Should PART be an $\mathrm{A} \beta$-independent cause of AD-type dementia, it may be an exception that helps to establish the validity of the amyloid cascade hypothesis.

\section{Funding}

The author is supported by the Alzheimer's Association (NIRG-15-363188), NIH (R01AG054008, R01NS095252, R01NS086736, and P50AG005138), and the Department of Defense (13267017).

\section{References}

1. Cipriani G, Dolciotti C, Picchi L, Bonuccelli U. Alzheimer and his disease: a brief history. Neurological sciences : official journal of the Italian Neurological Society and of the Italian Society of Clinical Neurophysiology. 2011;32(2):275-9. Epub 2010/12/15. doi: 10.1007/ s10072-010-0454-7. PubMed PMID: 21153601.

2. Hardy JA, Higgins GA. Alzheimer's disease: the amyloid cascade hypothesis. Science. 1992;256(5054):184-5. Epub 1992/04/10. PubMed PMID: 1566067.

3. Goate A, Chartier-Harlin MC, Mullan M, Brown J, Crawford F, Fidani L, et al. Segregation of a missense mutation in the amyloid precursor protein gene with familial Alzheimer's disease. Nature. 1991;349(6311):7046. doi: 10.1038/349704a0. PubMed PMID: 1671712.

4. Sherrington R, Rogaev EI, Liang Y, Rogaeva EA, Levesque G, Ikeda M, et al. Cloning of a gene bearing missense mutations in early-onset familial Alzheimer's disease. Nature. 1995;375(6534):754-60. doi: 10.1038/375754a0. PubMed PMID: 7596406.

5. Levy-Lahad E, Wasco W, Poorkaj P, Romano DM, Oshima J, Pettingell WH, et al. Candidate gene for the chromosome 1 familial Alzheimer's disease locus. Science. 1995;269(5226):973-7. PubMed PMID: 7638622 .

6. Rogaev EI, Sherrington R, Rogaeva EA, Levesque G, Ikeda M, Liang Y, et al. Familial Alzheimer's disease in kindreds with missense mutations in a gene on chromosome 1 related to the Alzheimer's disease type 3 gene. Nature. 1995;376(6543):775-8. doi: 10.1038/376775a0. PubMed PMID: 7651536.

7. Wisniewski KE, Wisniewski HM, Wen GY. Occurrence of neuropathological changes and dementia of Alzheimer's disease in Down's syndrome. Annals of neurology. 1985;17(3):278-82. doi: 10.1002/ana.410170310. PubMed PMID: 3158266.

8. Corder EH, Saunders AM, Strittmatter WJ, Schmechel DE, Gaskell PC, Small GW, et al. Gene dose of apolipoprotein E type 4 allele and the risk of Alzheimer's disease in late onset families. Science. 1993;261(5123):921-3. Epub 1993/08/13. PubMed PMID: 8346443.

9. Hardy J, Selkoe DJ. The amyloid hypothesis of Alzheimer's disease: progress and problems on the road to therapeutics. Science. 2002;297(5580):353-6. Epub 2002/07/20. doi: 10.1126/ science.1072994297/5580/353 [pii]. PubMed PMID: 12130773.
10.Hardy J. The amyloid hypothesis for Alzheimer's disease: a critical reappraisal. Journal of neurochemistry. 2009;110(4):1129-34. Epub 2009/05/22. doi: 10.1111/j.1471-4159.2009.06181.x. PubMed PMID: 19457065.

11. Khachaturian ZS. Diagnosis of Alzheimer's disease. Archives of neurology. 1985;42(11):1097-105. Epub 1985/11/01. PubMed PMID: 2864910.

12.Braak H, Braak E, Bohl J. Staging of Alzheimer-related cortical destruction. Eur Neurol. 1993;33(6):403-8. Epub 1993/01/01. PubMed PMID: 8307060.

13. Mirra SS. The CERAD neuropathology protocol and consensus recommendations for the postmortem diagnosis of Alzheimer's disease: a commentary. Neurobiology of aging. 1997;18(4 Suppl):S91-4. Epub 1997/07/01. PubMed PMID: 9330994.

14.Consensus recommendations for the postmortem diagnosis of Alzheimer's disease. The National Institute on Aging, and Reagan Institute Working Group on Diagnostic Criteria for the Neuropathological Assessment of Alzheimer's Disease. Neurobiology of aging. 1997;18(4 Suppl):S1-2. Epub 1997/07/01. PubMed PMID: 9330978.

15.Hyman BT, Phelps CH, Beach TG, Bigio EH, Cairns NJ, Carrillo MC, et al. National Institute on Aging-Alzheimer's Association guidelines for the neuropathologic assessment of Alzheimer's disease. Alzheimer's \& dementia : the journal of the Alzheimer's Association. 2012;8(1):1-13. Epub 2012/01/24. doi: 10.1016/j.jalz.2011.10.007. PubMed PMID: 22265587; PMCID: 3266529.

16. Montine TJ, Phelps CH, Beach TG, Bigio EH, Cairns NJ, Dickson DW, et al. National Institute on Aging-Alzheimer's Association guidelines for the neuropathologic assessment of Alzheimer's disease: a practical approach. Acta neuropathologica. 2012;123(1):1-11. Epub 2011/11/22. doi: 10.1007/s00401-011-0910-3. PubMed PMID: 22101365; PMCID: 3268003.

17. Nelson PT, Alafuzoff I, Bigio EH, Bouras C, Braak H, Cairns NJ, et al. Correlation of Alzheimer disease neuropathologic changes with cognitive status: a review of the literature. Journal of neuropathology and experimental neurology. 2012;71(5):362-81. Epub 2012/04/11. doi: 10.1097/NEN.0b013e31825018f7. PubMed PMID: 22487856; PMCID: 3560290.

18. Mirra SS, Heyman A, McKeel D, Sumi SM, Crain BJ, Brownlee LM, et al. The Consortium to Establish a Registry for Alzheimer's Disease (CERAD). Part II. Standardization of the neuropathologic assessment of Alzheimer's disease. Neurology. 1991;41(4):479-86. Epub 1991/04/01. PubMed PMID: 2011243.

19. Hyman BT, Trojanowski JQ. Consensus recommendations for the postmortem diagnosis of Alzheimer disease from the National Institute on Aging and the Reagan Institute Working Group on diagnostic criteria for the neuropathological assessment of Alzheimer disease. Journal of neuropathology and experimental neurology. 1997;56(10):1095-7. Epub 1997/11/05. PubMed PMID: 9329452.

20. Braak H, Braak E. Staging of Alzheimer's disease-related neurofibrillary changes. Neurobiology of aging. 1995;16(3):271-8; discussion 8-84. Epub 1995/05/01. PubMed PMID: 7566337.

21. Braak H, Braak E. Staging of Alzheimer-related cortical destruction. Int Psychogeriatr. 1997;9 Suppl 1:257-61; discussion 69-72. Epub 1997/01/01. PubMed PMID: 9447446.

22. Karran E, Mercken M, De Strooper B. The amyloid cascade hypothesis for Alzheimer's disease: an appraisal for the development of therapeutics. Nature reviews Drug discovery. 2011;10(9):698-712. Epub 2011/08/20. doi: 10.1038/nrd3505. PubMed PMID: 21852788.

23.Toyn JH, Ahlijanian MK. Interpreting Alzheimer's disease clinical trials in light of the effects on amyloid-beta. Alzheimers Res Ther. 2014;6(2):14. Epub 2014/07/18. doi: 10.1186/alzrt244. PubMed PMID: 25031632; PMCID: 4014014. 
24. Hyman BT. Amyloid-dependent and amyloid-independent stages of Alzheimer disease. Archives of neurology. 2011;68(8):1062-4. Epub 2011/04/13. doi: 10.1001/archneurol.2011.70. PubMed PMID 21482918 .

25. Nelson PT, Trojanowski JQ Abner EL, Al-Janabi OM, Jicha GA, Schmitt FA, et al. "New Old Pathologies": AD, PART, and Cerebral Age-Related TDP-43 With Sclerosis (CARTS). Journal of neuropathology and experimental neurology. 2016;75(6):482-98. Epub 2016/05/23. doi: 10.1093/jnen/nlw033. PubMed PMID: 27209644.

26. Hansen L, Salmon D, Galasko D, Masliah E, Katzman R, DeTeresa R, et al. The Lewy body variant of Alzheimer's disease: a clinical and pathologic entity. Neurology. 1990;40(1):1-8. Epub 1990/01/01. PubMed PMID 2153271.

27. Ghetti B, Oblak AL, Boeve BF, Johnson KA, Dickerson BC, Goedert M. Invited review: Frontotemporal dementia caused by microtubuleassociated protein tau gene (MAPT) mutations: a chameleon for neuropathology and neuroimaging. Neuropathology and applied neurobiology. 2015;41(1):24-46. Epub 2015/01/06. doi: 10.1111/ nan.12213. PubMed PMID: 25556536; PMCID: 4329416.

28. Kovacs GG. Invited review: Neuropathology of tauopathies: principles and practice. Neuropathology and applied neurobiology. 2015;41(1):323. Epub 2014/12/17. doi: 10.1111/nan.12208. PubMed PMID: 25495175 .

29. McKee AC, Stein TD, Nowinski CJ, Stern RA, Daneshvar DH, Alvarez VE, et al. The spectrum of disease in chronic traumatic encephalopathy. Brain : a journal of neurology. 2013;136(Pt 1):43-64. Epub 2012/12/05. doi: 10.1093/brain/aws307. PubMed PMID: 23208308; PMCID: 3624697.

30. Jellinger KA, Attems J. Neurofibrillary tangle-predominant dementia: comparison with classical Alzheimer disease. Acta neuropathologica. 2007;113(2):107-17. Epub 2006/11/08. doi: 10.1007/s00401-0060156-7. PubMed PMID: 17089134.

31. Crary JF, Trojanowski JQ Schneider JA, Abisambra JF, Abner EL, Alafuzoff I, et al. Primary age-related tauopathy (PART): a common pathology associated with human aging. Acta neuropathologica. 2014;128(6):755-66. Epub 2014/10/29. doi: 10.1007/s00401-0141349-0. PubMed PMID: 25348064; PMCID: 4257842.

32. Jack CR, Jr. PART and SNAP. Acta neuropathologica. 2014;128(6):7736. Epub 2014/11/09. doi: 10.1007/s00401-014-1362-3. PubMed PMID: 25380757; PMCID: 4231211.

33. Spencer PS, Nunn PB, Hugon J, Ludolph AC, Ross SM, Roy DN, et al. Guam amyotrophic lateral sclerosis-parkinsonism-dementia linked to a plant excitant neurotoxin. Science. 1987;237(4814):517-22. PubMed PMID: 3603037.
34. McNamara J, Murray TA. Connections Between Herpes Simplex Virus Type 1 and Alzheimer's Disease Pathogenesis. Current Alzheimer research. 2016;13(9):996-1005. PubMed PMID: 26971936.

35.Santa-Maria I, Haggiagi A, Liu X, Wasserscheid J, Nelson PT, Dewar K, et al. The MAPT H1 haplotype is associated with tangle-predominant dementia. Acta neuropathologica. 2012;124(5):693-704. Epub 2012/07/18. doi: 10.1007/s00401-012-1017-1. PubMed PMID: 22802095; PMCID: 3608475.

36.Janocko NJ, Brodersen KA, Soto-Ortolaza AI, Ross OA, Liesinger AM, Duara R, et al. Neuropathologically defined subtypes of Alzheimer's disease differ significantly from neurofibrillary tangle-predominant dementia. Acta neuropathologica. 2012;124(5):681-92. Epub 2012/09/13. doi: 10.1007/s00401-012-1044-y. PubMed PMID: 22968369; PMCID: 3483034.

37.McKee AC, Cantu RC, Nowinski CJ, Hedley-Whyte ET, Gavett BE, Budson $\mathrm{AE}$, et al. Chronic traumatic encephalopathy in athletes: progressive tauopathy after repetitive head injury. Journal of neuropathology and experimental neurology. 2009;68(7):709-35. Epub 2009/06/19. doi: 10.1097/NEN.0b013e3181a9d503. PubMed PMID: 19535999; PMCID: 2945234.

38. Klintworth GK. Paratentorial Grooving of Human Brains with Particular Reference to Transtentorial Herniation and the Pathogenesis of Secondary Brain-stem Hemorrhages. Am J Pathol. 1968;53(3):391408. Epub 1968/09/01. PubMed PMID: 19971046; PMCID: 2013461.

39. McKee AC, Stern RA, Nowinski CJ, Stein TD, Alvarez VE, Daneshvar DH, et al. The spectrum of disease in chronic traumatic encephalopathy. Brain : a journal of neurology. 2013;136(Pt 1):43-64. Epub 2012/12/05. doi: 10.1093/brain/aws307. PubMed PMID: 23208308; PMCID: 3624697.

40.Braak H, Del Tredici K. Are cases with tau pathology occurring in the absence of Abeta deposits part of the AD-related pathological process? Acta neuropathologica. 2014;128(6):767-72. Epub 2014/11/02. doi: 10.1007/s00401-014-1356-1. PubMed PMID: 25359108.

41. Duyckaerts C, Braak H, Brion JP, Buee L, Del Tredici K, Goedert M, et al. PART is part of Alzheimer disease. Acta neuropathologica. 2015. Epub 2015/01/30. doi: 10.1007/s00401-015-1390-7. PubMed PMID: 25628035.

42.Itoh Y, Yamada M, Suematsu N, Matsushita M, Otomo E. An immunohistochemical study of centenarian brains: a comparison. Journal of the neurological sciences. 1998;157(1):73-81. PubMed PMID: 9600680.

43.Small SA, Duff K. Linking Abeta and tau in late-onset Alzheimer's disease: a dual pathway hypothesis. Neuron. 2008;60(4):534-42. Epub 2008/11/29. doi: 10.1016/j.neuron.2008.11.007. PubMed PMID: 19038212; PMCID: 2692134. 